\title{
Assessing the role of the RND efflux pump in metronidazole resistance of Helicobacter pylori by RT-PCR assay
}

\author{
Jalil Fallah Mehrabadi ${ }^{1}$, Mehrandokht Sirous ${ }^{2}$, Naser Ebrahimi Daryani ${ }^{3}$, Saeed Eshraghi ${ }^{2}$, Bahram \\ Akbari $^{4}$, Mohammad Hasan Shirazi ${ }^{2}$ \\ ${ }^{1}$ MARS Bioinformatics Institute, Tehran, Iran \\ ${ }^{2}$ Department of Pathobiology, School of Public Health, Tehran University of Medical Sciences, Tehran, Iran \\ ${ }^{3}$ Department of Gastroenterology, Imam Khomeini Hospital, Tehran University of Medical Sciences, Tehran, Iran \\ ${ }^{4}$ Department of Bacteriology, School of Medicine, Tarbiat Modares University, Tehran, Iran
}

\begin{abstract}
Introduction: Metronidazole is a significant antibiotic used for eradication of Helicobactor pylori infections and it is of notice that metronidazole-resistant clinical isolates have been found in high rates worldwide. While the RND family of efflux pumps plays a central role in drug resistance among Gram-negative bacteria, this is questionable for H. pylori.

Methodology: To understand whether TolC homologues of RND pumps contribute to metronidazole resistance in $H$. pylori isolates, expression of four TolC homologous genes of five resistant clinical isolates exposed to varying concentrations of metronidazole were evaluated by RT-PCR and transcriptional analysis.

Results: The results indicate that excess amounts of metronidazole are able to increase the expression level of these genes at the transcriptional stage.

Conclusions: Therefore, it may be hypothesized that use of metronidazole in H. pyori infection can induce metronidazole resistance. Furthermore, the RND family of efflux pumps may contribute to metronidazole resistance in clinical isolates of $H$. pylori.
\end{abstract}

Key words: H. pylori; metronidazole; RND efflux pump

J Infect Dev Ctries 2011; 5(2):088-093.

(Received 11 May 2010 - Accepted 14 October 2010)

Copyright $\odot 2011$ Mehrabadi et al. This is an open-access article distributed under the Creative Commons Attribution License, which permits unrestricted use, distribution, and reproduction in any medium, provided the original work is properly cited.

\section{Introduction}

Helicobacter pylori is a Gram-negative, microaerophilic bacterium, caused peptic ulcer, chronic gastritis and gastric adenocarcinoma, which colonizes in the stomach of more than $50 \%$ of people [1,2]. Metronidazole is an antibiotic involved in the treatment of infection caused by $H$. pylori [3]. Metronidazole-resistant isolates can decrease the effect of such a treatment [4].

Five families of multidrug efflux pumps are recognized in bacteria which contribute to resistance against important drugs [5]. Over-expression of efflux pumps may be the initial stage in bacterial resistance to antibiotics [6]. The resistancenodulation-division (RND) family is one of the efflux pumps, which was originally discovered in Gramnegative bacteria [7]. The RND efflux pumps are tripartite systems including a membrane fusion protein (AcrA), an inner-membrane protein (AcrB), and an outer-membrane protein (TolC) [8]. TolC and its homologues are concerned with extrusion of various molecules and have a crucial role in the generation of pathogenicity and drug resistance in bacteria [9]. It has been shown that TolC produces channels in the lipid bilayer membrane and plays a role in the export of antibiotics beyond the outer membrane of E. coli $[10,11]$.

The four established TolC homologues in $H$. pylori, HP0605, HP0971, HP1327, and HP1489, are of interest in current research [12,13]. Bina et al. identified three RND efflux systems in $H$. pylori and demonstrated mutagenesis of operons in three RND efflux systems hefABC, hefDEF, and hefGHI that have no effect on the susceptibility of $H$. pylori to antibiotics [13]. Amsterdam et al. showed that an HP0605 knockout mutant is more susceptible to novobiocin, while an HP0605 and HP0971 doubleknockout mutant is more susceptible to metronidazole [14]. Kutschke and De Jonge created three isogenic mutants for hefC, hefF, hefI genes in $H$. pylori and subsequently identified antibiotic susceptibility of these mutants and their wild types. 
They demonstrated that the $h e f C$ gene has a role as a component of RND efflux systems in $H$. pylori [15]. Liu et al. assessed the hefA gene expression in mutant multiple drug resistance (MDR) strains and wild types and proposed that the hefA gene of efflux pumps contributes to resistance of $H$. pylori to antibiotics [16].

The present study aimed to determine whether metronidazole interacts with over-expression of RND efflux pump genes and also whether this antibiotic can cause bacteria to be converted into resistant strains. To evaluate the contribution of RND efflux pumps to resistant strains of $H$. pylori, we used different metronidazole concentrations to assess the expression of four $H$. pylori TolC homologous efflux pumps, namely HP0605, HP0971, HP1327 and HP1489. Our results indicated that over-expression of these genes correlated with an increase in concentration of metronidazole in the growth medium. Therefore, the RND efflux pump has a significant role in the contributing to metronidazole resistance in $H$. pylori.

\section{Methodology}

H. pylori isolates and growth conditions

A total of 104 antral gastric biopsy specimens were obtained from patients with gastritis or peptic ulcer undergoing endoscopy at the Laleh hospital, Tehran. The sample collection protocol was approved by the ethical committee of Tehran University of Medical Sciences, Tehran, Iran. During the endoscopy, two biopsy samples were taken for urease test and culture. Biopsies samples were transported in normal saline solution (at $4^{\circ} \mathrm{C}$ ) to the laboratory for culture. Biopsy samples were cultured on Brucella agar (Merck, Darmstadt, Germany) containing 10\% defibrinated sheep blood, 7\% fetal calf serum (FCS), $10 \mathrm{mg} / \mathrm{l}$ of vancomycin, $5 \mathrm{mg} / \mathrm{l}$ of trimethoprim, 20 $\mathrm{U} / \mathrm{ml}$ polymyxin $\mathrm{B}$, and $5 \mathrm{mg} / \mathrm{l}$ amphotericin $\mathrm{B}$ (Merck, Darmstadt, Germany,). Plates were incubated at $37^{\circ} \mathrm{C}$ under micro-aerophilic conditions (10\% CO2, 5\% O2, 85\% N2, Merck Camp Gas Pak) for five to seven days. Their identification as $H$. pylori was confirmed by Gram strain, oxidase, catalase, and urease tests.

\section{Susceptibility testing and MIC determination}

Susceptibility of $H$. pylori isolates to metronidazole was determined by the disk diffusion method. A saline suspension of isolates equivalent to $2 \mathrm{McF}$ arland standard $(1 \times 107-1 \times 108 \mathrm{cfu} / \mathrm{ml})$ was prepared from three-day-old culture. Aliquots $(5 \mu \mathrm{l})$ of the suspension were spread on Muller-Hinton agar (Merck, Darmstadt, Germany,) supplemented with 5\% defibrinated sheep blood and 7\% FCS, and a metronidazole disk (5 $\mu \mathrm{g}$ Himedia) was afterward placed on the surface of the medium and incubated for three days at $37^{\circ} \mathrm{C}$ under micro-aerophilic conditions. Susceptibility results were recorded as being resistant to metronidazole in a growth inhibition zone $\leq 16 \mathrm{~mm}[17,18]$.

For minimal inhibitory concentration (MIC) determination tests, isolates were tested by standard agar dilution method as described by Clinical and Laboratory Standard Institute (CLSI) [19]. MullerHinton agar supplemented with $5 \%$ defibrinated sheep blood and 7\% FCS contained serial dilutions in the range of $8-256 \mu \mathrm{g} / \mathrm{ml}$ of metronidazole. One plate without antibiotic was used as a control for each assay. Next, $5 \mu$ l of bacterial suspension equivalent to 2 McFarland was inoculated on the plates. Subsequently, the plates were incubated under microaerophilic conditions at $37^{\circ} \mathrm{C}$ for 72 hours. MIC was determined as the lowest concentration of metronidazole at which no colonies of bacterial growth were observed. Isolates were considered to be metronidazole-resistant when the growth was inhibited at metronidazole concentrations greater than $8 \mu \mathrm{g} / \mathrm{ml}$ (MIC $\geq 16 \mu \mathrm{g} / \mathrm{ml}$ ) [17]. H. pylori 26695 was used as a control in this study.

\section{Total RNA extraction}

Five isolates of metronidazole-resistant $H$. pylori were cultured on Muller-Hinton agar supplemented with 5\% defibrinated sheep blood, 7\% FCS, and 0, 8, and $16 \mu \mathrm{g} / \mathrm{ml}$ of metronidazole dilution. All plates were incubated at $37^{\circ} \mathrm{C}$ under micro-aerophilic conditions. Bacterial suspension was prepared in normal saline. The cells were then isolated by centrifugation $(9000 \times \mathrm{g}$ for $10 \mathrm{~min})$, and pellet was used for total RNA extraction.

RNA was isolated using RNAprotect bacteria reagent and RNaesy mini kit (QIAGEN, Hilden, Germany). The extracted RNA was treated with RNase free DNase I (Fermentas, Vilnius, Lithuania) according to the manufacture's protocol. Consequently, PCR was performed for detection of genomic DNA. Concentration of RNA was determined by biophotometer (Eppendorf, Hamburg, Germany).

\section{$R T-P C R$}

The reverse transcription-PCR (RT-PCR) analyses were conducted using a first strand cDNA 
Table 1. Genes used in the study

\begin{tabular}{|l|l|}
\hline Gene Name & Accession Number \\
\hline HP0605 & AAD07673 \\
\hline HP0971 & AAD08018 \\
\hline HP1327 & AAD08377 \\
\hline HP1489 & AAD08524 \\
\hline
\end{tabular}

synthesis kit (Fermentas, Vilnius, Lithuania). Briefly, $7 \mu \mathrm{l}$ of total $0.04 \mu \mathrm{g} / \mu \mathrm{l}$ RNA, $1 \mu \mathrm{l}$ random hexamer $(0.2 \mu \mathrm{g} / \mu \mathrm{l})$, and $4 \mu \mathrm{R}$ Rase-free water were incubated for 5 minutes at $70^{\circ} \mathrm{C}$, chilled on ice, followed by addition of $4 \mu \mathrm{l}$ of buffer (5x), $2 \mu \mathrm{l}$ dNTPs (10mM) and $1 \mu \mathrm{l}$ Ribolock $(20 \mathrm{u} / \mu \mathrm{l})$ to reaction, and they were afterward incubated for 5 minutes at $25^{\circ} \mathrm{C}$. Next, $1 \mu \mathrm{l}$ of reverse transcriptase was added to a $20 \mu \mathrm{l}$ final volume reaction. The reaction was incubated for 10 minutes at $25^{\circ} \mathrm{C}$ and then for 60 minutes at $42^{\circ} \mathrm{C}$. The final incubation was accomplished for 10 minutes at $70^{\circ} \mathrm{C}$.

PCR was performed in a $25 \mu \mathrm{l}$ final volume solution containing $2 \mu \mathrm{l}$ cDNA, $1.5 \mu \mathrm{l}$ of each primer (10 pmol), $1 \mu \mathrm{l}$ dNTPs $(10 \mathrm{mM}), 0.75 \mu \mathrm{l} \mathrm{Mgcl} 2$ (50 $\mathrm{mM}), 2.5 \mu \mathrm{l}$ buffer $(10 \mathrm{x})$, and $1 \mu \mathrm{l}$ Taq DNA polymerase $(1 \mathrm{u} / \mu \mathrm{l})$. The genes and primers used for PCR are presented in Tables 1 and 2. Primers were designed by the authors. The amplification reaction was one cycle for 3 minutes at $94^{\circ} \mathrm{C}$, followed by 35 cycles for 1 minute at $94^{\circ} \mathrm{C}, 1$ minute at $55^{\circ} \mathrm{C}, 1$ minute at $72^{\circ} \mathrm{C}$ and 1 cycle for 5 minutes at $72^{\circ} \mathrm{C}$. PCR products were detected in $1 \%$ agarose gel containing $1 \%$ ethidium bromide. H. pylori 26695 was used as a reference isolate. Finally, the bands on gel agarose were compared using Lab analyzer software for densitometry analysis [20]. The final results were compared with the optical density (OD) of total RNA.

\section{Results}

\section{Isolation of $\mathrm{H}$. pylori resistant to Metronidazole}

In this study, $35 \mathrm{H}$. pylori isolates were identified from 104 antral biopsies. The susceptibility tests were performed on the isolates and resistance to metronidazole was obtained in $51.5 \%$ of the $\mathrm{H}$. pylori isolates. In MIC determination, $94.11 \%$ and $5.88 \%$ of these isolates showed MIC values equal to 32 $\mu \mathrm{g} / \mathrm{ml}$ and $16 \mu \mathrm{g} / \mathrm{ml}$, respectively. We used five metronidazole-resistant isolates ( $\mathrm{MIC}=32 \mu \mathrm{g} / \mathrm{ml}$ ) for molecular analysis in our investigation.

Involvement of TolC homologues in $\mathrm{H}$. pylori resistance to metronidazole
Table 2. Primers used in this study

\begin{tabular}{|l|l|}
\hline $\begin{array}{l}\text { Primer } \\
\text { Name }\end{array}$ & Primer Sequence \\
\hline HP0605 FW & 5'-ACCGCTTGACTTTAGAATACC-3' \\
\hline HP0605 RV & 5'-ATTCAAAGTCGCAGTAACCC-3' \\
\hline HP0971 FW & 5'-GTATGTGCAACGAGAAGCG-3' \\
\hline HP0971RV & 5'-GATAGATATTTTTAGGCGTTACC-3' \\
\hline HP1327 FW & 5'-CTTTACCAAGCTAACCATTCC-3' \\
\hline HP1327 RV & 5'-AAAGGGATGGACAAAGCG-3' \\
\hline HP1489 FW & 5'-GTCTAACCATGAAGGCTTGC-3' \\
\hline HP1489 RV & 5'-GCTTATAATGGCCTTTTCC-3' \\
\hline FW - Forward RV - Reverse
\end{tabular}

To determine whether the over-expression of RND systems correlated with metronidazole resistance in clinical isolates of $H$. pylori, the expression of four TolC homologues in five metronidazole-resistant isolates was evaluated at transcription levels by RT-PCR. Total cellular RNA was investigated in different metronidazole concentrations. To further study the relationship between metronidazole concentration and the expression of RND systems in bacterial antibiotic resistance, we investigated the transcriptional expression of $H$. pylori TolC homologues in various concentrations of metronidazole. Densitometry analysis was conducted to measure the transcripts.

All five resistant isolates showed transcripts of the HP0605 gene in various concentrations of metronidazole. Each isolate exposed to $8 \mu \mathrm{g} / \mathrm{ml}$ of metronidazole had higher transcripts compared to those without metronidazole. Similar results were observed after exposure of $16 \mu \mathrm{g} / \mathrm{ml}$ of metronidazole. Therefore, the HP0605 gene expresses without metronidazole but over-expresses transcriptionally by increasing the concentration of antibiotic. Hence metronidazole can influence gene expression at the transcriptional level and may be involved in drug resistance to $H$. pylori.

Expression at the transcriptional level of the HP0971 gene was observed in three isolates. This gene was expressed after the exposure of metronidazole at various concentrations such as 0,8 , and $16 \mu \mathrm{g} / \mathrm{ml}$; however, in one isolate, the expression level was dependent on metronidazole concentrations. Limited gene expression was also observed without exposure to metonidazole. Similar results were observed in other isolates, where HP0971 transcript level was higher after exposure with high concentration of metronidazole such as 16 $\mu \mathrm{g} / \mathrm{ml}$ while no expression was observed in $0 \mu \mathrm{g} / \mathrm{ml}$. 
Table 3. Yields of gene expression in transcriptional level in $H$. pylori strains.

\begin{tabular}{|c|c|c|c|c|c|c|c|c|c|c|c|c|}
\hline \multirow{3}{*}{$\begin{array}{l}\text { Number of } \\
\text { samples }\end{array}$} & \multicolumn{12}{|c|}{ Gene names \& metronidazole concentration $(\mu \mathrm{g} / \mathrm{ml})$} \\
\hline & \multicolumn{3}{|c|}{ HP0605 } & \multicolumn{3}{|c|}{ HP0971 } & \multicolumn{3}{|c|}{ HP01327 } & \multicolumn{3}{|c|}{ HP1489 } \\
\hline & 0 & 8 & 16 & 0 & 8 & 16 & 0 & 8 & 16 & 0 & 8 & 16 \\
\hline 1 & + & ++ & +++ & - & - & - & - & - & - & - & - & - \\
\hline 2 & + & ++ & +++ & - & - & + & - & - & + & - & - & + \\
\hline 3 & + & ++ & +++ & - & - & - & - & - & - & - & - & - \\
\hline 4 & + & ++ & +++ & - & + & ++ & - & - & + & - & - & - \\
\hline 5 & + & ++ & +++ & + & ++ & +++ & - & - & - & - & - & - \\
\hline
\end{tabular}

In one isolate, expression at the transcriptional level of HP0971 was obtained only in $16 \mu \mathrm{g} / \mathrm{ml}$ of metronidazole. According to our study, metronidazole can be the reason for over-expression of HP0971 gene and may cause antibiotic resistance in H. pylori.

Two cinilical isolates expressed HP1327 gene and one isolate expressed HP1489 gene at the transcriptional levelonly after exposure at $16 \mu \mathrm{g} / \mathrm{ml}$ of metronidazole. The results of gene expression at the transcriptional level are summarized in Table 3. The data indicate that TolC homologues expression at the transcriptional level was higher in the presence of metronidazole, and the HP0605 gene was expressed more than the other three genes. The occurrence of over-expression of HP0605 and HP0971, along with the expression of HP1327 and HP1489 after exposure to antibiotics, supports the hypothesis that these genes have a role in antibiotic resistance. Metronidazole induces the efflux activity higher than the strains grown in a medium without it. These results suggest that TolC homologous genes are related to the development of $H$. pylori resistance to metronidazole.

\section{Discussion}

H. pylori antibiotic resistance is a growing problem and the consequent failure of antibiotic therapy results in a high rate of infections with resistant isolates [21,22]. Over-expression of efflux pumps in mutant strains is easily detected in posttherapy isolates $[23,24]$, thus confirming their roles in the acquired drug resistance of pathogenic bacteria [25].

Metronidazole has been selected as one of the main antibiotics for the treatment of $H$. pylori infections, reaching an acceptable eradication rate [26]. Metronidazole resistance is most common in $H$. pylori and remarkably reduces eradication rates [4,27]. In previous surveys, the role of RND efflux pumps in $H$. pylori has been studied; nevertheless, it was not established that these pumps influence drug resistance to $H$. pylori. Thus we assessed the effect of metronidazole on drug resistance related to efflux pumps in $H$. pylori. In the current study, the transcriptional level expression of four RND efflux pump genes (TolC homologous) namely HP0605, HP0971, HP1327 and HP1489, in H. pylori was measured at various concentrations of metronidazole. The results of this investigation indicate that expression of homologous TolC genes corresponds with an increase in metronidazole concentration. Accordingly, metronidazole can stimulate expression of these genes and also their over-expression occurs in higher doses of metronidazole.

RT-PCR analyses demonstrated that HP0605 was expressed significantly in the presence of metronidazole or without it, and was over-expressed in increased amounts of this antibiotic. HP0971 may express without metronidazole, but over-expressed in high levels of metronidazole. HP1327 and HP1489 did not express in common conditions while expression of these genes at the transcriptional level was detected in higher metronidazole concentrations. Bina et al. assessed the expression of three RND efflux operons, namely hefABC, hefDEF, and hefGHI in $H$. pylori. They evaluated the expression of hefC, hefF, and hefI genes in both in vivo and in vitro conditions by RT-PCR. Their results showed that hefC and hefF were expressed both in vivo and in vitro but hefI was expressed just in the former condition. Moreover, a mutant strain of $H$. pylori for these efflux genes did not show higher susceptibility than a wild type strain [13]. In contrast to the observations of Bina et al., in which the authors did not find any influence of the RND efflux systems of $H$. pylori in antibiotic resistance, we observed altered expression levels of these four genes in the presence of metronidazole that have not been noted earlier. However, the results of present study are consistent with those of a study by Van Amsterdam et al., who investigated the antibiotic susceptibility of the 
HP0605 knockout and HP1489 knockout mutants of H. pylori, and determined that the HP0605 knockout mutant is more susceptible to novobiocin and deoxycholate, whereas the HP1489 knockout mutant is more susceptible to dye ethidium bromide in comparison with wild type strains. They further demonstrated that susceptibility to metronidazole increased in the H0605 and HP0971 double knockout mutant [14].

Our findings are also in agreement with those of Kutschke and De Jonge, who demonstrated sensitivity to 20 compounds in a wild type strain of H. pylori and its three isogenic mutants (hefC, hefF, and $h e f I$ ). They distinguished excess susceptibility for nine compounds in the hefC mutant [15]. Our results also agree with the observations of Liu et al., who evaluated the expression of hefA gene in multidrug resistant mutants and their parents. Their study revealed a significant increase in the expression of the hefA gene in mutants of $H$. pylori. Furthermore, Liu and colleagues inactivated the hefA gene in $H$. pylori 26695 and determined the MIC for 10 antibiotics. Their results showed the decrease of MIC and they therefore illustrate the role of the hefA gene in drug resistance in $H$. pylori [16]. In previous studies, HP1327 and HP1489 have not been associated with antibiotic resistance. Thus the findings of the current investigation suggest that the effect of metronidazole on the expression of TolC homologues in $H$. pylori. RT-PCR results show that these genes have higher expression at the transcriptional level in the isolates grown in the presence of metronidazole than in common growth conditions. Therefore, these may potentially have a role in extrusion of metronidazole from the bacteria and also cause the resistance to this antibiotic in clinical $H$. pylori isolates subsequent to treatment with this antibiotic. In spite of these observations, a major limitation of this study is the genome diversity of $H$. pylori. The main cause of metronidazole resistance is point mutations among redox genes, which could influence efflux pump related antibiotic resistance patterns. It is therefore difficult to distinguish between these two antibiotic resistance mechanisms.

In conclusion, this study suggests that TolC homologues are significant factors leading to overexpression of efflux pumps and may result in increased metronidazole resistance in $H$. pylori. Further studies of TolC homologues should be performed to appropriately understand the roles of efflux pumps in $H$. pylori resistance to metronidazole.

\section{References}

1. Dunn BE, Cohen H, Blaser MJ (1997) Helicobacter pylori. Clin Microbiol Rev 10: 720-741.

2. International Agency for Research on Cancer, World Health Organization. Infection with Helicobacter pylori. (1994) In: International Agency for Research on Cancer (ed). Schistosomes, liver flukes and Helicobacter pylori. Lyon: IARC177-202.

3. Veldhuyzen van Zanten SJ, Sherman PM (1994) Indications for treatment of Helicobacter pylori infection: a systematic overview. Can Med Assoc J 150: 189-198.

4. Mégraud F (1998) Epidemiology and mechanism of antibiotic resistance in Helicobacter pylori. Gastroenterology 115: 1278-1282.

5. Paulsen IT (2003) Multidrug efflux pumps and resistance: regulation and evolution. Curr Opin Microbiol 6: 446-451.

6. Oethinger M, Kern WV, Jellen-Ritter AS, McMurry LM, Levy SB (2000) Ineffectiveness of topoisomerase mutations in mediating clinically significant fluoroquinolone resistance in Escherichia coli in the absence of the AcrAB efflux pump. Antimicrob Agents Chemother 44: 10-13.

7. Mahamoud A, Chevalier J, Alibert-Franco S, Kern WV, Pages JM (2007) Antibiotic efflux pumps in Gram-negative bacteria: the inhibitor response strategy. J Antimicrob Chemother 59: 1223-1229.

8. Misra R and Bavro VN (2009) Assembly and transport mechanism of tripartite drug efflux systems. Biochim Biophys Acta 1794: 817-825.

9. Sharff Andrew, Fanutti Cristina, Shi Jiye, Calladine Chris, Luisi Ben. (2001) The role of the TolC family in protein transport and multidrug efflux from stereochemical certainty to mechanistic hypothesis. Eur J Biochem 268: 5011-5026.

10. Benz R, Maier E, Gentshev I (1993) TolC of Escherichia coli functions as an outer membrane channel. J Bacteriol 178: 5803-5805.

11. Poole K (2000) Efflux-mediated resistance to fluoroquinolones in Gram-negative bacteria. Antimicrob Agents Chemother 44: 2233-2241.

12. Johnson JM, Church GM (1999) Alignment and structure prediction of divergent protein families: periplasmic and outer membrane proteins of bacterial efflux pumps. J Mol Biol 287: 695-715.

13. Bina JE, Alm RA, Uria-Nickelsen M, Thomas SR, Trust TJ, Hancock RE (2000) Helicobacter pylori uptake and efflux: basis for intrinsic susceptibility to antibiotics in vitro. Antimicrob Agents Chemother 44: 248-254.

14. Van Amsterdam K, Bart A, van der Ende A (2005) A Helicobacter pylori TolC efflux pump confers resistance to metronidazole. Antimicrob Agents Chemother 49: 14771482.

15. Kutschke Amy, de Jonge Boudewijn LM (2005) Compound efflux in Helicobacter pylori. Antimicrob Agents Chemother 49: 3009-3010.

16. Liu ZQ, Zheng PY, Yang PC (2008) Efflux pump gene hefA of Helicobacter pylori plays an important role in multidrug resistance. World J Gastroenterol 14: 5217-5222.

17. Chaves S, Gadanho M, Tenreiro R, Cabrita J (1999) Assessment of Metronidazole Susceptibility in Helicobacter pylori: Statistical Validation and Error Rate Analysis of 
Breakpoints Determined by the Disk Diffusion Test. J Clin Microbiol 37: 1628-1631.

18. McNulty $\mathrm{C}$ and the PHLS Helicobacter working group: Owen R, Tompkins D, Howtin P, McColl K, Price A, Smith G, Teare L (2001) Helicobacter pylori susceptibility testing by disk diffusion. J Antimicrob Chemother 49: 601-609.

19. CLSI (2005) Clinical and Laboratory Standards Institute. Performance Standards for Antimicrobial Susceptibility Testing: Fifteenth Informational Supplement M100-S15. CLSI, Wayne, PA, USA.

20. Ilka A Assmann, Georg A Enders, Jurgen Puls, Gabriele Rieder, Rainer Haas, Rudolf A Hatz (2001) Role of virulence factors, cell components and adhesion in Helicobacter pylori - mediated iNOS induction in murine macrophages. FEMS Immunol Med Mic 30: 133-138.

21. Dore MP, Leandro G, Realdi G, Sepulveda AR, Graham DY (2000) Effect of pretreatment antibiotic resistance to metronidazole and clarithromycin on outcome of Helicobacter pylori therapy: a meta-analytical approach. Dig Dis Sci 45: 68-76.

22. Heep M, Kist M, Strobel S, Beck D, Lehn N (2000) Secondary resistance among 554 isolates of Helicobacter pylori after failure of therapy. Eur J Clin Microbiol Infect Dis 19: 538-541.

23. Kohler T, Michea-Hamzehpour M, Plesiat P, Kahr AL, Pechere JC (1997) Differential selection of multidrug efflux systems by quinolones in Pseudomonas aeruginosa. Antimicrob Agents Chemother 41: 2540-2503.

24. Ziha-Zarifi I, Llanes C, Kohler T, Pechere JC, Plesiat P (1999) In vivo emergence of multidrug-resistant mutants of Pseudomonas aeruginosa overexpressing the active efflux system MexA-MexB-OprM. Antimicrob Agents Chemother 43: $287-291$

25. Linares JF, Lopez JA, Camafeita E, Albar JP, Rojo F, Martinez JL (2005) Overexpression of the Multidrug Efflux Pumps MexCD-OprJ and MexEF-OprN Is Associated with a Reduction of Type III Secretion in Pseudomonas aeruginosa. J Bacteriol 187: 1384-1392.

26. Bazzoli F, Zagari RM, Pozzato P, Fossi S, Ricciardiello L, Nicolini G, De Luca L, Berretti D, Alampi G, Di Pietro C, Morelli P, Roda E (2002) Low-dose lansoprazole and clarithromycin plus metronidazole vs. full-dose lansoprazole and clarithromycin plus amoxicillin for eradication of Helicobacter pylori infection. Aliment Pharmacol Ther 16: 153-158.

27. Mégraud F, Lehn N, Lind T, Bayerdorffer E, O'Morain, C, Spiller R, Unge P, van Zanten SV, Wrangstadh M, Burman CF (1999) Antimicrobial susceptibility testing of Helicobacter pylori in a large multicenter trial: The MACH 2 study. Antimicrob Agents Chemother 43: 2747-2752.

\section{Corresponding author}

Mohammad Hasan Shirazi

Bacteriology Unit, Department of Pathobiology

School of Public Health

Tehran University of Medical Sciences

Tehran, Iran

Fax: 02188954913

Email: mhshirazi@sina.tums.ac.ir

Conflict of interests: No conflict of interests is declared. 